\title{
The Anti-Science of Climate Change Advocates
}

\author{
Lawrence Southwick* \\ University at Buffalo, Buffalo, USA \\ Email: Is5@buffalo.edu
}

Received 13 February 2016; accepted 6 June 2016; published 9 June 2016

Copyright (C) 2016 by author and Scientific Research Publishing Inc.

This work is licensed under the Creative Commons Attribution International License (CC BY).

http://creativecommons.org/licenses/by/4.0/

(c) (i) Open Access

\section{Abstract}

I do not know whether anthropogenic climate change is occurring. However, I know that I do not know. There are numerous others who also do not know whether anthropogenic climate change is occurring. However, they appear not to know that they do not know. Worse, they are asserting that they do know. In order to be able to make valid decisions in respect of the issue, the science will have to be dramatically improved. This paper is written with the aim of promoting such scientific improvement, particularly in defining the concept of climate change. It also includes a way of testing some of the most important claims of climate alarmists without the necessity of actually defining climate change, along with examples of the appropriate tests (which all give negative results).

\section{Keywords}

Climate, Science, Convictions, Operational Definitions, Models

\section{Introduction}

There are a number of problems with the methods used by climate change scientists to derive their conclusions. The first section of this paper will deal with some of these. In particular, methods that are invalid will be described and refuted. These include "majority opinion", disagreements with others, "settled science", using the same data to derive and test hypothesis, inductive reasoning, and a refusal to reveal the methods and/or data used.

\footnotetext{
${ }^{*}$ Emeritus Assoc. Prof. of Management Science, University at Buffalo. I would note that I have received no financial support from anyone for my research on this topic. (As an emeritus faculty member, I am, however, entitled to free internet access.).
} 


\section{Science Problems}

\subsection{Majority Rule}

The first major anti-science item is the frequent claim that a very large majority of the involved scientists are in agreement that anthropogenic climate change is occurring. There is an implicit (and frequently explicit) implication that anyone who disagrees with this majority must be in error. Of course, science is not determined by a majority vote. A very apt quotation in that regard is given by Galileo, "In questions of science the authority of a thousand is not worth the humble reasoning of a single individual” ${ }^{1}$. Science is not determined by voting.

\subsection{Dealing with Those Who Disagree}

While only a few will generally attempt to silence those who disagree with them ${ }^{2}$, the number who do so is not zero; there are some currently trying to keep others from speaking out ${ }^{3}$. In some cases, it is difficult for a minority opinion to get any hearing. There does not have to be an explicit rejection to have this effect. When the standard for the inclusion of someone's research in the body of research in the area is that it be "peer-reviewed", the first paper accepted for publication has to overcome potential reviewers' initial hesitation in a new field because there is not yet a body of accepted research. It is odd but true that some 20 university professors who ought to support free speech have very recently suggested using RICO to silence others ${ }^{4}$. It ought to be asked whether that is felonious or simply anti-science.

\subsection{Science Is Settled}

It has been argued by the climate change advocates that "the science is settled". This may be interpreted as implying that it would be futile to do any more research. That is a violation of the scientific method; to a true scientist science is NEVER settled. In fact, to a real scientist, this implies that the person saying it is a charlatan. It is often very difficult to get people who are set in their beliefs to change, even with good new evidence. From the early $20^{\text {th }}$ century, it was believed that ulcers were caused by stress and diet. Two Australian physicians, J. Robin Warren and Barry Marshall, found in 1983 [1] that it is a bacterium, H. Pylori, which causes ulcers. Even by 1995, 12 years later, only 5 percent of U.S. ulcer patients were treated with antibiotics. Other examples where science was not "settled" include Einstein's modification of Newton's theory, Heisenberg's finding the Uncertainty Principle, and Schrodinger's Quantum Mechanics. At this point, are we really sure about "dark matter” or "dark energy"? It is not settled. There are numerous other examples.

\subsection{Using One Set of Data to Create Hypothesis and to Test That Same Hypothesis}

A true scientist will not use one set of data to generate hypothesis and then use the same set of data to test that hypothesis. The information used in creating the hypothesis must be from sources other than the data to be used in testing the hypothesis. It appears that Climate Change advocates use various data and then fit a model to that data, never actually testing the model. Sometimes, data from several sources are used simultaneously, another science violation. The fitted model is then used to make predictions. Properly, the predictions should be then tested against future data, gathered after the predictions are made. Thus, if the model predicts higher temperatures 50 years in the future, the predicted temperatures should be compared with the actual temperatures 50 years later.

\footnotetext{
${ }^{1}$ Galileo Galilei (15 Feb. 1564-8 Jan. 1642); Italian natural philosopher who believed the Earth revolved around the Sun. For this, he was interrogated by the Inquisition, was put on trial, found guilty and sentenced to indefinite imprisonment. For renouncing his former beliefs before the Cardinals that judged him, he was allowed to serve this time instead under house-arrest. The Pope approving this sentence was Urban VIII

${ }^{2}$ One Senator, Sheldon Whitehouse, suggested that the RICO statute be used against those who disagree with the climate change activists. That would be applying major civil or criminal sanctions against those like Galileo who do not agree with the orthodoxy, thus criminalizing free speech.

${ }^{3}$ Recently, the Federal Emergency Management Agency has threatened states that do not agree with anthropogenic climate change with reduced funding for disaster planning. This qualifies as threatening dissenters. Also, a group of professors urged that the Federal Government prosecute people who disagree under RICO (a criminal statute). It is worth noting that many of those attempting to silence dissenters are supported by government and apparently do not see their own conflict of interest. In 2016, it appears that the US “Justice Department" has been directed by the US Attorney General to investigate whether dissenters might be prosecuted. Government and science are in direct conflict here.

${ }^{4}$ Six of the 20 were from George Mason University, to its shame.
} 


\subsection{Using a Model Based Solely on Fitting Past Data Does Not Allow for Any Inference That Would Be Meaningful ${ }^{5}$}

As Karl Popper [2] has noted, "no matter how many instances of white swans we may have observed, this does not justify the conclusion that all swans are white". Popper proposes, op. cit., page 6, that deductive testing of theories be done. In this methodology, the theory is used to derive deductively the consequences of the theory. If the deductive conclusions appear to be confirmed by whatever experiments are used, the theory is not rejected for the moment. He says, "I shall not require of a scientific system that it shall be capable of being singled out, once and for all, in a positive sense; but I shall require that its logical form shall be such that it can be singled out, by means of empirical tests, in a negative sense: it must be possible for an empirical scientific system to be refuted by experience." 6

Consider the following from Scientific American, June 29, 2011. John Carey [3] said that "Scientists used to say, cautiously, that extreme weather events were "consistent" with the predictions of climate change." No more. "Now we can make the statement that particular events would not have happened the same way without global warming," says Kevin Trenberth [4], head of climate analysis at the National Center for Atmospheric Research (NCAR). That is not a scientific conclusion because he has certainly not exhausted the possibilities and could not even have known all of the possibilities.

\subsection{Changing Data Bases}

Barbara Fraser [5], in National Geographic on Feb. 27, 2015 argues that climate change caused drought in part of Brazil as well as floods in other areas. In order to define climate change in some area, it will not be appropriate to use varying locations for the definition. One cannot use some area for the hypothesis and then another area to test that. Mann and Emanuel link hurricanes with climate change ${ }^{7}$. Willie Drye [6] reviews a study that proposes that "The warming caused by greenhouse gases-thought to be the result of human activities such as burning fossil fuels - could redirect atmospheric winds that steer hurricanes.” By the next century, the study's authors report, atmospheric winds over the Atlantic could blow more directly from west to east during hurricane season, pushing storms away from the United States. The paper was written by meteorologists Elizabeth Barnes [7] at Colorado State University; Lorenzo M. Polvani of Lamont-Doherty Earth Observatory in Palisades, New York; and Adam H. Sobelband at Columbia University. If climate change in theory causes both droughts and floods and more severe weather and less severe weather, this is certainly not a falsifiable theory. In fact, it is not a usable theory at all; a theory that predicts that weather will be either more violent or less violent and either wetter or drier is necessarily true (adding the possibility of no change). Another report by Accuweather basically comes down to a result that there has been no difference over time in tornadoes ${ }^{8}$.

Popper, op. cit., page 24, said "Every experimental physicist knows those surprising and inexplicable apparent 'effects' which in his laboratory can perhaps even be reproduced for some time, but which finally disappear without trace. Of course, no physicist would say in such a case that he had made a scientific discovery (though he might try to rearrange his experiments so as to make the effect reproducible). Indeed the scientifically significant physical effect may be defined as that which can be regularly reproduced by anyone who carries out the appropriate experiment in the way prescribed. No serious physicist would offer for publication, as a scientific discovery, any such 'occult effect', as I propose to call it—one for whose reproduction he could give no instructions. The 'discovery' would be only too soon rejected as chimerical, simply because attempts to test it would lead to negative results."

\footnotetext{
${ }^{5}$ If the university acts in concert with government, should we not object to that collusion? Is it not a conspiracy to deprive people of their free speech rights?

${ }^{6} \mathrm{He}$ goes on to say (page 18) that "Theories are NEVER empirically verifiable” because induction is not an acceptable method of proof. Popper proposes that "the work of the scientist consists of putting forward and testing theories" of how the world works.

${ }^{7}$ Mann, M.E., Emanuel, K.A., Atlantic Hurricane Trends linked to Climate Change, Eos, 87, 24, p 233, 238, 241, 2006.

${ }^{8}$ Accuweather is a private firm that competes with the National Weather Service. Since the former charges for its service while the latter provides its service without charge, it follows that for both to continue in existence implies that Accuweather must, on average, be better at forecasting than the latter. It is not necessarily perfect; just enough better to be more valuable on balance to the purchaser.

${ }^{9}$ In the literature of physics there are to be found some instances of reports, by serious investigators, of the occurrence of effects that could not be reproduced, since further tests led to negative results. A well-known example from recent times is the unexplained positive result of Michelson's experiment observed by Miller (1921-1926) at Mount Wilson, after he himself (as well as Morley) had previously reproduced Michelson's negative result. But since later tests again gave negative results it is now customary to regard these latter as decisive, and to explain Miller’s divergent result as 'due to unknown sources of error'. *See also section 22, especially footnote *1.
} 


\subsection{Unwillingness to Make the Experimenter's Data or Methods Public}

Unfortunately, many of those who have purportedly proved Global Warming or Climate Change results have simply refused to reveal their methodologies or their original data. Accordingly, they have not, in those cases, done any genuine scientific research. One must reveal the precise methodology and data so that the results can be replicated or rejected by others ${ }^{10}$. I would suggest that those who refuse to reveal their methods and data are concerned that their results will not withstand examination. They also should have their activities viewed as worthless.

\subsection{A Scientist's Convictions or Certainty}

Popper goes on to say, "I may be utterly convinced of the truth of a statement; certain of the evidence of my perceptions; overwhelmed by the intensity of my experience: every doubt may seem to me absurd. But does this afford the slightest reason for science to accept my statement? Can any statement be justified by the fact that I am utterly convinced of its truth? The answer is, 'No'; and any other answer would be incompatible with the idea of scientific objectivity. Even the fact, for me to so firmly established, that I am experiencing this feeling of conviction, cannot appear within the field of objective science except in the form of a psychological hypothesis which, of course, calls for intersubjective testing: from the conjecture that I have this feeling of conviction the psychologist may deduce, with the help of psychological and other theories, certain predictions about my behaviour; and these may be confirmed or refuted in the course of experimental tests. But from the epistemological point of view, it is quite irrelevant whether my feeling of conviction was strong or weak; whether it came from a strong or even irresistible impression of indubitable certainty (or 'self-evidence'), or merely from a doubtful surmise. None of this has any bearing on the question of how scientific statements can be justified" "11. See, for example the EPA's assertion that Earth is warming. "Scientists are highly confident that many of these observed changes can be linked to the climbing levels of carbon dioxide and other greenhouse gases in our atmosphere, which are caused by human activities"12. That is certainly not evidence that it is actually warming or that any such increase in carbon dioxide actually has caused warming. This is precisely what Popper warned us about.

There are those who are certain that their feelings about climate change are clearly correct. They are the ultracrepidarians such as Mr. Obama and the Pope who are certain of their preconceptions and do not accept other views as possibly being correct. However, they are definitely not scientists and are not worthy of being believed on climate change. Others who claim to be scientists (anyone may make that claim, but it is their evidence which makes that claim true or false, not the claim itself).

\subsection{Models as Evidence}

Many of the reports state that their high degree of confidence in their forecasts is due to their models that are fitted to the data. Having a regression result for this curve fitting on past data is not evidence and should not be thought of in that way. This is especially important for forecasting. Some years ago, the Club of Rome, a group of economists (many at MIT) used such curve fitting for making extrapolations as economic forecasts. Naturally, these proved extremely fallible. They were very poor forecasting tools. Extrapolating trend lines is an easy way to produce bad forecasts. (People do respond to changing conditions in defiance of the assumption otherwise).

Any time a fitted model is used as a representation of reality it will have some built-in errors. These errors then accumulate the longer the time period to be forecasted. This then implies wildly varying errors as forecasts are for longer time periods. A forecast for a century or a millennium will have little or no predictive power for such long period forecasts. Reliance on these will produce little accuracy. (Of course, the forecaster is relieved of the responsibility for his forecast since he cannot be proved wrong prior to his demise.)

\footnotetext{
${ }^{10}$ I once asked an author for the data he used in a paper on gun ownership and crime and was refused. I then asked the New England Journal of Medicine (where that paper was published) to require that author to make the data available and was refused. I would suggest that this indicates that both the author and the $\mathbf{N E} \boldsymbol{J M}$ are neither reliable nor performing real science. (By the way, that author did admit that the data was made up by himself).

${ }^{11}$ Popper, op cit, Chapter 1, “A survey of some fundamental problems”, page 25.

${ }^{12}$ See: EPA's Climate Change: Basic Information, “The evidence is clear. Rising global temperatures have been accompanied by changes in weather and climate. Many places have seen changes in rainfall, resulting in more floods, droughts, or intense rain, as well as more frequent and severe heat waves. The planet's oceans and glaciers have also experienced some big changes - oceans are warming and becoming more acidic, ice caps are melting, and sea levels are rising. As these and other changes become more pronounced in the coming decades, they will likely present challenges to our society and our environment.”
} 
Simulation is the use of prior outcomes to establish probabilities of various outcomes of random events. These estimated probabilities are used with a number of random number drawings to predict future outcomes.

This can approach validity only if past outcomes are distributed exactly the same as future outcomes. This is the functional equivalent of correlating variables with outcomes. The estimated parameters are then used for projections.

Because of the assumptions, any errors will be compounded over time for future predicted events.

\subsection{Assertions without Evidence}

The United States Environmental Protection Agency (EPA) provides some information on a website ${ }^{13}$. Unfortunately, this "Basic Information" is mainly assertions without evidence. It starts by stating "Our Earth is Warming" and "The Evidence is Clear" and "Humans are largely responsible for recent climate change". These are unproved statements. Remember that the primary reason for moving the debate to "climate change" was that the forecasts of "global warming" were proved invalid. Thus, the Earth warming claim had already been proved invalid. Again, an assertion is not evidence (except of the asserter not being a true scientist). The operational definitions of "Climate" and "Climate Change" remain undefined.

The National Climate Assessment [8] reports that "Climate change is contributing to increases in wildfires across the western US and Alaska." This is based on increasing "deforestation". However, in US Forest Facts and Historical Trends, the U.S. forest area has decreased by less than 1.4 percent over the 90 years from 1907 to $1997^{14}$. Another result comes from Wildfire Today; that is a negative correlation of 0.14 between the Year and the annual number of wildfires from 1985 through $2014^{15}$. The claim of increasing wildfires and the attribution to "climate change" must therefore be false ${ }^{16}$. However, the more people build their houses in risky places (a trend accentuated by government subsidized insurance), the greater the damage of any fire is likely to be ${ }^{17}$.

Another paper argues that if carbon dioxide increases for some time period, the effects will be irreversible for a very long time period, more than 1000 years ${ }^{18}$. This is based on "advances in modeling". It is then argued that "X percent of models show...". This is clearly not real science. Using a fitted model and drawing conclusions by projecting forward is not even worthy as a good hypothesis. Now, if the authors want to test their model, it will require a waiting period of at least 1000 years to determine whether the extrapolated results actually occur ${ }^{19}$.

The IPCC Fourth Assessment Report makes the following assertion ${ }^{20}$ : "There is considerable confidence that climate models provide credible quantitative estimates of future climate change, particularly at continental scales and above. This confidence comes from the foundation of the models in accepted physical principles and from their ability to reproduce observed features of current climate and past climate changes. Confidence in model estimates is higher for some climate variables (e.g., temperature) than for others (e.g., precipitation). Over several decades of development, models have consistently provided a robust and unambiguous picture of significant climate warming in response to increasing greenhouse gases.” However, models are not evidence, so this is again not science.

In fact, this assertion violates the precepts of good science. An untested model cannot give any forecasts with any confidence. When a model is created, the next step is to test it. It appears that none of the models made up by the so-called climate scientists is actually tested. This implies that none of their models can be relied upon for any forecasting.

The typical testing is properly done as follows: the model is used to make predictions under two conditions, first that condition A obtains and second that condition B (often expressed as not A) obtains. In this case, those conditions might be that atmospheric carbon dioxide is increasing and that atmospheric carbon dioxide is not in-

\footnotetext{
${ }^{13}$ EPA's Climate Change: Basic Information, May 18, 2015. “Climate Change is happening”.

${ }^{14}$ Of course, the linkage between some definition of climate change and wildfires has yet to be made because climate change is not adequately defined.

${ }^{15}$ The mean was 75,254 and the std. dev. was 12,498.

${ }^{16}$ The Wall Street Journal reported (Thurs., Sept. 3, 2015), page A9, that a new estimate of the number of trees in the world by the Yale School of Forestry is 3.04 trillion while it was earlier estimated by satellite imagery that the number was 400 billion. This suggests that much of the forest fire damage data may well be worthless.

${ }^{17}$ Of course, the more atmospheric oxygen taken up as carbon dioxide, the less combustion will be supported by the atmosphere; (this probably will be a very small effect.) Remember that CO2 is used to extinguish fires.

${ }^{18}$ See Susan Solomon, et al., National Academy of Sciences.

${ }^{19}$ Nicholas Stern also uses model projections as though they were valid

${ }^{20}$ IPCC Climate Change 2007, FAQ 8.1.
} 
creasing. The predictions of the model under each scenario are made and then compared with real world results.

\subsection{Human Effects Asserted}

Human Effects Asserted-Does Mankind Cause Climate Change? This is the major point argued by the climate changers. If this were not the objective of those who want to use government to forcibly change the use of combustible sources of energy, there would probably be little controversy. However, it is an interesting question, particularly because mankind's ability to actually affect weather has never been shown ${ }^{21}$.

Appendix 3 of the Climate Science Supplement states unequivocally that "human activities are the dominant agents of change" affecting climate. Figure 2, page 738, presents the (estimated) incoming energy and the outgoing energy for Earth.

Now this is a point where hypothesis may be developed although it is not explicitly asserted. The following is such hypothesis. More energy arriving at Earth's surface than is leaving the surface should result in warming ${ }^{22}$. Figure 2, page 738, shows an estimation of the "surface imbalance" of 0.6 watts per square meter $+/-17$ watts per square meter. (I assume this is annually, not that this really matters for the test) ${ }^{23}$.

Let us assume that the figures above were empirically derived and that the estimates are for a normal distribution. That is, the standard deviation is 17 watts per square meter. The range for the 95 percent confidence interval then is from +33.92 watts per square meter to -32.72 watts per square meter. This gives very little confidence that the true amount is actually positive. How should this be used in actually forecasting any change? It would seem that the answer should be "not at all". Do we really want to reduce economic activity by a substantial fraction based on something as uncertain as this?

This Appendix also tells us in Supplemental Message 4 that the methodology is "detection and attribution". This is, as it is described, simply using the data to create the theory and then testing the theory with that same data. It is not in any way valid "science". The simulations used cannot be in any way considered or used for a valid test of the theory. This is not science. It may be useful for criminal forensics since that is historical only, but it is not science as we are using the term.

On page 747 of this Appendix, this "Full Report” again includes Mann's infamous "hockey stick” temperature graph ${ }^{24}$. This was fully discredited in 2003 by McIntyre and McKitrick ${ }^{25}$. This result embarrassed the climate changers to the extent that it no longer appeared in the U.N.'s climate change reports. However, it has now been resurrected in the most recent report where it says that the decade from 2001-2010 is the "warmest on record" over the last 1700 years. Well, no, it may well not have been. See, for example, the uncertainties in the data as reported by Spencer ${ }^{26}$.

\subsection{What Is a "Good" Climate?}

Suppose we could change the climate. What climate would we choose? Jan Null, of Golden Gate Weather Services, has actually created such an index. While many will disagree with either the items used in the index or with the weightings, it provides ratings and could be adjusted for individual preferences. Of course, we really can't adjust the actual weather for individual places, but this indicates some of the difficulties that would be present if we could adjust as desired.

Null used Temperature-Humidity Indexes for both high average and low average temperature as the discom-

\footnotetext{
${ }^{21}$ The 1956 film, "The Rainmaker”, has the actor Burt Lancaster as a con man promising to end a drought in a Kansas town. The drum is beaten and eventually rain comes. (Of course, love comes as well.)

${ }^{22}$ See Climate Change Science Supplement, Appendix 3, Climate Change Impacts in the United States, page 738, Figure 2. John Walsh, Donald Wuebbles, Katherine Hayhoe, et al.

${ }^{23}$ On page 747 of this Appendix, this “Full Report” again includes Mann’s infamous “hockey stick” temperature graph. This first appeared in 1998 and was fully discredited by McIntyre, Stephen; and McKitrick, Ross (2003). “Corrections to the Mann et al. (1998) Proxy Data Base and Northern Hemispheric Average Temperature Series”. Energy \& Environment 14(6): 751-771. This embarrassed the climate changers to the extent that it no longer appeared in the U.N.'s climate change reports. However, it has now been resurrected in this latest report where it says that the decade from 2001-2010 is the “warmest on record” over the last 1700 years. Well, no, it wasn’t. See Spencer, et al.

${ }^{24}$ Mann, Michael E.; Bradley, Raymond S.; Hughes, Malcolm K. (23 April 1998), “Global-scale temperature patterns and climate forcing over the past six centuries”, Nature 392 (6678): 779-787, Bibcode: 1998 Natur. 392. 779M, doi: 10.1038/33859. They had two time series from different sources and simply connected these end to end.

${ }^{25}$ McIntyre, Stephen; McKitrick, Ross (2003), Energy \& Environment 14.

${ }^{26}$ http://www.drroyspencer.com/2015/04/version-6-0-of-the-uah-temperature-dataset-released-new-lt-trend-0-11-cdecade/.
} 
fort measures as above. He also used precipitation and sunshine indexes. These were combined to give an overall index for about 150 cities in the US. The index value of 100 was for the "perfect weather". He then mapped the iso-index curves across the US for the 1981-2010 normals. The high value was for San Diego, CA, at 89 and the low city was 51 for Juneau, AK. This is the Camelot Index, named after the 1960s musical.

Not everyone will agree on the ideal. Thus, even if we could influence climate, something for which we have no evidence, there would be difficulties in choosing our climate. Therefore, for government to pick a desirable climate is something which it should not do. Of course, the government is claiming that it is simply choosing to oppose any anthropogenic changes. As shown above, there is no real evidence for such changes, (and no evidence that such changes can be made) so government can only, at best, waste resources in its efforts.

It is not even clear that having a higher temperature is harmful (keeping in mind that the current issue is not global warming but "climate change"). Warmer growing areas could well produce more food. Also, keep in mind that carbon dioxide is a raw material in food production. It is a "greenhouse gas", often used in greenhouses to promote plant growth.

\subsection{Operationally Defining Climate Change}

Neither "climate" nor "climate change" has, to my knowledge, been adequately defined operationally (see Sir Percy Bridgeman 1927). If we are to be discussing some concept in a way so as to have the meaning understood by different persons in a consistent way, it will be necessary to have some such definition. If, for example, we are to define "wind velocity" as the average anemometer reading for all anemometers currently available, that will not be the same as the average person's perceptions of how windy it is now nor will all anemometers register alike, particularly at different altitudes or latitudes ${ }^{27}$.

An operational definition of the variables in any hypothesis is necessary, in Sir Percy Bridgeman's view ${ }^{28}$. This can also be viewed more simply; if you have not defined a variable so you can measure it, you cannot be assured of communicating correctly what you mean by naming it. (The current issue, "climate change", was previously called "global warming" until it failed the test of actually showing temperature increases being associated with carbon dioxide. At that time, the global warming alarmists then shifted to an as yet undefined "climate change" which presumably would be associated with changes in atmospheric carbon dioxide.)

\subsection{NASA's Definition: Weather vs Climate}

Let's take a look at the meaning attached to climate by NASA; What's the Difference between weather and climate? What Climate Means ${ }^{29}$. "In short, climate is the description of the long-term pattern of weather in a particular area. Some scientists define climate as the average weather for a particular region and time period, usually taken over 30-years. It's really an average pattern of weather for a particular region. When scientists talk about climate, they're looking at averages of precipitation, temperature, humidity, sunshine, wind velocity, phenomena such as fog, frost, and hail storms, and other measures of the weather that occur over a long period in a particular place. For example, after looking at rain gauge data, lake and reservoir levels, and satellite data, scientists can tell if during a summer, an area was drier than average. If it continues to be drier than normal over the course of many summers, than it would likely indicate a change in the climate.” A little further on, NASA goes on (op cit.) to say "NASA has been using satellites to study Earth's changing climate. Thanks to satellite and computer model technology, NASA has been able to calculate actual surface temperatures around the world and measure how they've been warming. To accomplish the calculations, the satellites actually measure the Sun's radiation reflected and absorbed by the land and oceans."

However, despite all this NASA apparent certainty, there do not appear to be actual measurements of climate or climate change that are fully operationally determined. Take the NASA definition. That certainly does not give a measure of climate at any time. By an operational definition, according to Bridgeman, 1927, page 5; "we mean by any concept nothing more than a set of operations; the concept is synonymous with the corresponding set of operations." Thus, in order to define "climate" the operations necessary to measure it must be precisely specified. Inasmuch as NASA has not specified the physical actions to define climate such as average precipitation over some time period in some place, this definition is not operationally defined. In fact, their definition is

\footnotetext{
${ }^{27}$ In the US, many weather gathering sites are at airports. Their business models often result in more buildings and more paving with the result of creating ever-larger heat islands.

${ }^{28}$ See, for example, page 5 in his Logic of Modern Physics, Macmillan, 1927.

${ }^{29}$ http://www.nasa.gov/mission_pages/noaa-n/climate/climate weather.html
} 
effectively circular; climate change is a change in the weather that is persistent over some time period.

Let us start with a list of the climate measures. Take the one from NASA, above. That gives 8 listed measures, plus "other (unspecified) measures of the weather". Further, measures of data distributions will be needed. Suppose we end up with 40 or 50 measures, including the distribution measures for each point in time. Of course, there will also be differences across space; that is; the measures at a point in time will vary over the defined region. That region may be as small as a mile or less in diameter. For instance, rain may be falling in one place while there is no rain falling some small distance away. It must be remembered that each of these measures of variables must still be specified in an operational sense; how, specifically, each is measured. Then, it will be necessary to collect the many measures of all the variables over the time period under consideration ${ }^{30}$. Then, how does each measure interact with the others to determine a single measure defining climate?

\subsection{Measuring a Single Variable}

It is difficult to measure even one of these listed measures of climate, let alone all of them, plus the measures which aren't listed. Consider wind velocity. At what elevation should this be taken? Should this be at local ground level or some elevation above sea level? Keep in mind that Miami is very close to sea level while Denver is about a mile above sea level. That difference may well affect observations of wind velocity. These measures will frequently be widely variable. Let us suppose as an example that the measured ground wind velocities over a 16 hour period in some locality are 4 hours of wind at $20 \mathrm{mph}$ from the north, 4 hours of wind at $30 \mathrm{mph}$ from the south, 4 hours of wind at $10 \mathrm{mph}$ from the east, and 4 hours of wind at $10 \mathrm{mph}$ from the west. What is the average? Would that be equivalent to 16 hours from the south at $10 \mathrm{mph}$ ? Would it be 16 hours at $17.5 \mathrm{mph}$ ? It might be 16 hours at 4 miles per hour (the net distance a frictionless paper is moved). All of these depend on how the average is to be computed. Each of the above examples is based on some net effect. We will need some convention by which various researchers agree to make measurements.

One such is a Wind Index ${ }^{31}$. These are generally found in Europe and are based on the productivity of wind turbines. A number of turbines are checked for their productivity each month. This provides an average that can be used to compute deviations from that average. Deficiencies in turbine performance or in amounts of wind can be inferred. Most such wind indexes are designed for use in creating or evaluating wind power plants, including location determinations. I have not seen how this would work for comparing a steady $20 \mathrm{mph}$ wind with a gusty wind of 50 percent of the time calm and 50 percent of the time at $40 \mathrm{mph}$. Certainly the latter would be less useful for a power plant than would the former. It has been argued that winds in northwest Europe are particularly volatile, so such a measure would not be appropriate for evaluating a climate measure for the U.S.

We could also look at extremes. The Mount Washington Observatory ${ }^{32}$ reported that they had recorded a wind velocity of $231 \mathrm{mph}$ on April 12, 1934. That record stood until 1996 when Barrow Island, Australia recorded a new record of $253 \mathrm{mph}$. It is doubtful that such maxima will be of much use in constructing a wind index for the purpose of defining climate.

This does not even satisfy the issue of defining the variable sufficiently to determine that a change has occurred and thus to infer that a change in that variable has changed sufficiently to determine that a climate change has occurred. It appears that there is no way to develop an index of the climate and to definitively determine a change in climate.

\section{Alternative Tests}

\subsection{Developing an Alternative Test for the Climate Problems Posited}

There may well be an alternative test for the presence of carbon dioxide problems which are suppose to be present through climate change effects. This could work even though there is no evidence for climate changes caused by carbon dioxide. Such an alternative test would necessarily avoid using the term climate change because it is simply undefined.

The following is a method of accomplishing a test of something resembling the climate change hypothesis. It

${ }^{30}$ Because I moved from Buffalo, NY, to Sarasota, FL, I notice some differences in the weather. (How's that for an understatement?) Climate is local. In fact, the weather in Sarasota is noticeably different from the weather in Tampa, 50 or so miles to the north, or Fort Myers, 50 or so miles to the south, at the same time.

${ }^{31}$ See "Definition of a wind index", Wind Power Monthly, January 2006

${ }^{32}$ Look up MWOBS (Mount Washington Observatory) on the Internet. Or, see:

https://www.mountwashington.org/about-us/history/world-record-wind.aspx 
is a bit less direct, but avoids the necessity of adequately defining climate change operationally. That, as we have seen, has not been done. In order to do this alternative test, note that the focus has not been on simply climate change but rather on the projected consequences of "climate change". These consequences have been generally thought to be adverse.

The typical reasoning is: 1) carbon dioxide causes climate change; 2) climate change causes some adverse consequence; and 3) the adverse change results in some problem. Think of this as reasoning that: (A) $\mathrm{CO}_{2}$ causes climate change and (B) climate change causes the adverse result (C).

Logically, this is: (A) causes (B) and (B) causes (C). We can simplify this reasoning by deleting the variable "climate change". Then the equivalent reasoning becomes: (A) causes (C). It does not really differ from (A) causes (B) and (B) causes (C) except by deleting the undefined intervening variable (B). (B) is not really needed and the logic remains the same. In this method, a test has to be developed for each of the adverse consequences anticipated from the increase in carbon dioxide.

The independent variable in each of these tests is the $\mathrm{CO}_{2}$ concentrations. These are collected by the Scripps Institution of Oceanography at Mauna Loa in Hawaii on a monthly basis. These data are made available from the Scripps $\mathrm{CO}_{2}$ Program ${ }^{33}$. Presumably, $\mathrm{CO}_{2}$ gets distributed around the Earth fairly uniformly whatever its source so we can reasonably use these data. At least that appears to be the assumption by those who argue that carbon dioxide is the proximate cause of the projected ills.

There are several consequences projected by the climate alarmists. These include tornadoes, wildfires, hurricanes, drought, and precipitation. Let us consider each of these:

\subsection{Tornadoes and $\mathrm{CO}_{2}$}

One of the major predictions is for more and stronger storms, particularly tornadoes ${ }^{34}$. Let $\mathrm{C}$ be tornadoes and A be carbon dioxide. The Tornado History Project, giving the numbers of tornadoes each year since 1950, is available on-line thanks to Joshua Lietz and data from the Storm Prediction Center ${ }^{35}$.

Typically, the larger tornadoes are counted as being more significant. In sparsely settled areas, smaller tornadoes may easily be uncounted. This is less likely to happen in more recent years. Also, the larger tornadoes have greater capacity for damage. Using the Fujita Scale, the tornadoes to be included are the F3, F4, and F5 while F0, $\mathrm{F} 1$, and F2 tornadoes are not counted.

The result of regressing annual tornadoes on $\mathrm{CO}_{2}$ over the 1959-2012 period, using annual data is:

$$
\begin{array}{llll}
\text { Tornadoes } & =155.03-0.314 \mathrm{CO}_{2} & \\
\mathrm{SE} & (42.88) & (0.123) & \mathrm{r}^{2}=0.11 \\
\text { t-Statistics } & 3.616 & -2.561 & \mathrm{DF}=52
\end{array}
$$

Inasmuch as the slope coefficient fails to be significantly positive, the result is that there is not a positive relationship between $\mathrm{CO}_{2}$ and tornadoes. It follows that either $\mathrm{CO}_{2}$ does not cause climate change or climate change does not cause tornadoes (or both) ${ }^{36}$. That is, the proposed conclusion of $\mathrm{CO}_{2}$ causing tornadoes is not supported. Thus, the hypothesis is found to be invalid.

\section{3. $\mathrm{CO}_{2}$ and Wildfires}

Next, let us look at wildfires ${ }^{37}$. The argument is that increased $\mathrm{CO}_{2}$ results in Climate Change that, in turn, re${ }^{33}$ See Scripps Institute of Oceanography. http://scrippsco2.ucsd.edu

${ }^{34}$ For example see 'Climate Change Guide” in About News, "Does Climate Change Cause Extreme Weather?” http://environment.about.com/od/globalwarmingandweather/a/Does-Climate-Change-Cause-Extreme-Weather.htm; From About.com, "Economic Impact of Climate Change", Argues that tornadoes are the result of climate change.

http://useconomy.about.com/od/criticalssues/fl/Economic-Impact-of-Climate-Change.htm; From Nature Conservancy, "Change Impacts”. "Climate change will cause storms, hurricanes and tropical storms to become more intense."

http://www.nature.org/ourinitiatives/urgentissues/global-warming-climate-change/threats-impacts/stronger-storms.xml; From EPA, "Impacts from Extreme Weather Events”. This argues for more extreme weather

http://www3.epa.gov/climatechange/impacts/health.html\#impactsextremeweather

${ }^{35}$ http://www.tornadohistoryproject.com/browse

${ }^{36}$ It would appear that the result is that increasing $\mathrm{CO}_{2}$ actually may cause fewer major tornadoes, but that was not the objective of this test so the only result claimed here is that increased $\mathrm{CO}_{2}$ does not cause increased tornadoes.

${ }^{37}$ Nature Conservancy, 2015, Climate Change will cause "Increased Risk of Drought, Fire, and Floods, Stronger Storms and Increased Storm Damage, More Heat-Related Illness and Disease”. http://www.nature.org/ourinitiatives/urgentissues/global-warming-climate-change/threats-impacts/drought-fire-floods.xml 
sults in increased Wildfires. For our test here, that hypothesis can be simplified to: increased $\mathrm{CO}_{2}$ results in increased Wildfires.

The data on Wildfires comes from the National Interagency Fire Center ${ }^{38}$ and includes the years from 1985 through 2014. The regression result is:

$$
\begin{aligned}
& \text { Fires }=\quad 124778-133.76 \mathrm{CO}_{2} \\
& \begin{array}{llll}
\mathrm{SE} & \text { (54415) } & (146.84) & \mathrm{r}^{2}=0.028
\end{array} \\
& \text { t-Statistics }=2.29 \quad(-0.91) \quad \mathrm{DF}=28
\end{aligned}
$$

The slope coefficient is not significantly positive. It follows that the claimed effect does not pass the test. Either $\mathrm{CO}_{2}$ does not cause climate change or climate change does not cause wildfires (or both). Again, the hypothesis is invalidated.

\section{4. $\mathrm{CO}_{2}$ and Hurricanes}

Now, consider Hurricanes and the effect of $\mathrm{CO}_{2}$ on them. There are 5 categories of hurricanes on the SaffirSimpson Hurricane Wind Scale. As with the tornadoes, the 3 major categories will be included in this test. Those hurricanes with winds of 74 - 95 mph (Category 1) and 96 - 110 mph (Category 2) will be left out. Those with winds of 110 - $129 \mathrm{mph}$ (Category 3), 130 - $156 \mathrm{mph}$ (Category 4), and 157+ (Category 5) will be included. Data for the numbers of hurricanes in each category for 1959 through 2014 are given by NOAA's Hurricane Research Division ${ }^{39}$.

The regression result is:

$$
\begin{array}{llll}
\text { Major Hurricanes }= & -2.795+0.014896 \mathrm{CO}_{2} & \\
\text { SE } & (3.438) & (0.00978) & \mathrm{r}^{2}=0.041 \\
\text { t-Statistics } & -0.81 & 1.528 & \mathrm{DF}=54
\end{array}
$$

Because the slope coefficient is not significantly positive, it follows that the claimed effect does not pass the test. Either $\mathrm{CO}_{2}$ does not cause climate change or climate change does not cause hurricanes (or both). The hypothesis is not accepted.

\section{5. $\mathrm{CO}_{2}$ and Drought}

Another stated effect of $\mathrm{CO}_{2}$ is to cause increased drought ${ }^{40}$. Now, drought is an interesting thing to measure. The Palmer Drought Severity Index PDSI ${ }^{41}$ [9] is probably the most widely used. For information about this index, see: National Weather Service-Climate Prediction Center, Explanation ${ }^{42}$. For the data, see: NOAA, National Centers for Environmental Information, "Historical Palmer Drought Indexes"

Because PDSI does not take snow and ice into consideration, I have chosen to limit the dataset to the figures for July in each year to minimize the effect that solid water would have on the data. Of course, I have also limited the $\mathrm{CO}_{2}$ data in each year to July as well. The data are then available for 1958 through 2014.

The test here is to see whether $\mathrm{CO}_{2}$ has an effect on the average drought for the country. Note that the issue is not whether the drought is in a different location but whether there is more or less drought. Drought, like many

\footnotetext{
${ }^{38}$ National Interagency Fire Center, Total Wildland Fires and Acres, 1960-2014. This gives the data for number of annual fires and the acres burned. Before 1983, the data are essentially deleted as unconfirmed and not comparable to later data. (The numbers of fires were originally well over 100,000 per year in those years.) In 1984 and 1985, the numbers were 18,000 and 20, 000, so far below the later data that they need to be deleted as anomolous as well, Thus, I have used only the 1985 through 2014 data for this test.

${ }^{39}$ See: http://www.aoml.noaa.gov/hrd/tcfaq/E11.html

${ }^{40}$ Center for Disease Control, “Climate Effects on Health”, 12-22-2014. See Chapter 2 "Key weather and climate drivers of health impacts include increasingly frequent, intense, and longer-lasting extreme heat, which worsens drought, wildfire, and air pollution risks; increasingly frequent extreme precipitation, intense storms, and changes in precipitation patterns that lead to drought and ecosystem changes”. http://nca2014.globalchange.gov/report/sectors/human-health

${ }^{41}$ See: “review of available drought indexes”, ws-Final_droughtindices, http://drought.unl.edu/planning/monitoring/comparisonofindicesintro.aspx

${ }^{42}$ http://www.cpc.ncep.noaa.gov/products/analysis monitoring/cdus/palmer drought/wpdanote.shtml

${ }^{43}$ http://www.ncdc.noaa.gov/temp-and-precip/drought/historical-palmers/psi/190007-201507
} 
other weather related conditions, does not necessarily stay in a constant place. However, the average over the whole country could be affected by the $\mathrm{CO}_{2}$ levels. (Increasing drought-greater water shortfall is found with increasingly negative numbers on the measure.)

The resulting regression result is:

$$
\begin{array}{lll}
\text { Average Drought }= & 5.501-0.0139 \mathrm{CO}_{2} & \\
\mathrm{SE} & (4.722)(0.0134) & \mathrm{r}^{2}=0.019 \\
\text { t-Statistics } & 1.165-1.0366 & \mathrm{DF}=55
\end{array}
$$

The slope coefficient is not significantly negative; it follows that the claimed effect does not pass the test. Either $\mathrm{CO}_{2}$ does not cause climate change or climate change does not cause drought (or both). The hypothesis fails.

\section{6. $\mathrm{CO}_{2}$ and Precipitation}

It may seem odd to test both drought and precipitation against $\mathrm{CO}_{2}$ since they would seem to be opposites. However, what they are measuring is dissimilar enough to warrant that testing. Thus, we need to test for higher rainfall as a consequence of $\mathrm{CO}_{2}$ rising ${ }^{44}$. Some predict higher and some predict lower rainfall as a $\mathrm{CO}_{2}$ caused consequence, although most predict higher rainfall ${ }^{45}$. We already have the annual measures for $\mathrm{CO}_{2}$ from above. The annual precipitation amounts can be derived from the NOAA data as indicated above. Data for both is from 1959 to 2014.

The regression of $\mathrm{CO}_{2}$ on Average Annual Rainfall is given below:

$$
\begin{aligned}
& \text { Average Annual Rainfall }=27.48+0.0087 \mathrm{CO}_{2} \\
& \text { SE (3.94) (0.0112) } \quad r^{2}=0.011 \\
& \text { t-Statistics } \quad 6.973 \quad 0.7767 \quad \mathrm{DF}=54
\end{aligned}
$$

While I have used annual data in the above because the time period typically used in climate change discussions is around 30 years $^{46}$, it is sometimes possible to use monthly data. The result would be, in this case,

$$
\begin{aligned}
& \text { Average Monthly Rainfall }=2.1506+0.00114 \mathrm{CO}_{2} \\
& \text { SE } \\
& (0.3625)(0.00198) \quad r^{2}=0.00197 \\
& \text { t-Statistics } \\
& 5.9321 .0883 \quad \mathrm{DF}=598
\end{aligned}
$$

It would appear here that generally, any increase in rainfall somewhere is cancelled out over the time period involved by decreased rainfall elsewhere. It needs to be kept in mind that the climate change model requires increases or decreases over the average. Increases in some area accompanied by decreases over another area does not imply any change in the average climate. This result is that $\mathrm{CO}_{2}$ appears to have no significant effect on precipitation. The hypothesis fails.

\section{7. $\mathrm{CO}_{2}$ and Heat Related Deaths/Cold Related Deaths}

It is argued by some that increasing heat will cause more deaths ${ }^{47}$. However, with less cold weather, there will be fewer cold-related deaths. The Lancet [10] published a study on this and found that "Most of the tempera-

\footnotetext{
${ }^{44}$ For example, consider the following by the Natural Resources Defense Council on The consequences of Global Warming on Weather Patterns, Higher temperatures could lead to increased droughts and wildfires, heavier rainfall, and a greater number of Category 4 and 5 hurricanes". http://www.nrdc.org/globalwarming/fcons/fcons1.asp

${ }^{45}$ EPA Climate Change, Climate Change Impacts and Adapting to Change, "climate change can increase or decrease rainfall”. http://www3.epa.gov/climatechange/adaptation/

${ }^{46}$ See EPA “Glossary of Climate Change Terms".

${ }^{47}$ Beaudry, Frederic, in about.news, "heat waves are routinely responsible for fatalities among the elderly”. Nature Conservancy, Climate Change Impacts, "In 2003, for example, extreme heat waves caused more than 20,000 deaths in Europe and more than 1500 deaths in India. Scientists have linked the deadly heat waves to climate change and warn of more to come.” Also, "The World Health Organization (WHO) estimates that climate change may have caused more than 150,000 deaths in the year 2000 alone, with an increase in deaths likely in the future.” See also Climate Change Guide, "What are the Effects of Climate Change? ... “Already, millions of people are dying each year”.
} 
ture-related mortality burden was attributable to the contribution of cold. The effect of days of extreme temperature was substantially less than that attributable to milder but non-optimum weather. This evidence has important implications for the planning of public-health interventions to minimize the health consequences of adverse temperatures, and for predictions of future effect in climate-change scenarios." Of course, the effect of $\mathrm{CO}_{2}$ on temperature has been seen earlier as a failed prediction.

\subsection{Other Poorly Specified Predictions}

These include a rise in the sea level. There is not a well defined effect here so it cannot be tested. Sea level is also not well specified. (Also, while there is really only one ocean, there is not a single level at any time.)

Species extinction is projected to increase. Because we don't even have a very good fix on the number of extant species or any way to determine extinctions, this cannot be tested.

Predicted increasing acidity of the oceans. This has not been measured in any consistent way, nor is the acidity level consistent across oceans. (National Geographic says that over the past 300,000,000 years, the acidity has gone from 8.2 to 8.1. See National Geographic, Enriq Sala).

\section{Conclusion}

There are two conclusions that result from this paper. First, there is no real operational definition of Climate Change. Thus, we cannot rely on that concept in any study. Second, there is another way to develop and test the major issues in the climate change literature. Using that method which simplifies the concepts and actually testing for those conclusions reveal that the disasters proposed to result from climate change do not result and cannot be supported as actual results.

\section{References}

[1] Barry Warren \& Robin Marshall, NBC News, 1983.

[2] Popper, K. (1980) The Logic of Scientific Discovery. Taylor and Francis E-Library.

[3] Carey, J. (2011) Global Warming and the Science of Extreme Weather. Scientific American, 6/29/2011.

[4] Trenberth, K. (2013) on NPR, 23 August 2013, 5:47 PM ET.

[5] Fraser, B. (2015) Quirky Winds Fuel Brazil’s Devastating Drought, Amazon’s Flooding. National Geographic, 27 February 2015.

[6] Drye, W. (2013) Climate Change May Offer Hurricane Help. National Geographic, 4 September 2013.

[7] Barnes, Polvani, Sobelband, (2013) Proceedings of the National Academy of Science, 2 August, 2013.

[8] National Climate Assessment (No. 4), May 2014.

[9] Fuchs, B. (2012) Palmer Drought Severity Index (PSDI and scPDSI). National Drought Mitigation Center, University of Nebraska-Lincoln, Caribbean Drought Workshop, 22-24 May 2012.

[10] Gasparrini, A., Guo, Y., Hashizume, M., Lavigne, E., Zanobetti, A., Schwartz, J., et al. (2015) Mortality Risk Attributable to High and Low Ambient Temperature: A Multicountry Observational Study. Lancet, 386, 369-375. 